\title{
Forest fires, risk and control
}

\author{
H. Azari \\ University College of Borås, School of Engineering, Sweden
}

\begin{abstract}
Fire is known as a primitive and amazing effect of nature and for humans it can be a friend, source of light and heat. Human intervention and ignoring nature's rules can lead to an out of control forest fire, changing its face into an uncontrollable force. Through the thesis work, more than 450 articles, scientific papers, and web-pages have been studied and reviewed to find points and comments that might help to reduce the fire occurrence probabilities, fire aggression, and damage to people, the environment, and the economy.

Ten years of work experience in industrial safety and fire fighting has been applied to new findings in the field of forest fires. There are many points and comments reviewed in the thesis document and here through this paper some specific results are been discussed. The introduction of the concept of layer protection to this study has been attempted, in which preventive and remedial measures are the two main schemes for reducing unwanted incidents and their probable consequences. To prevent the risk, deviation should be indicated, while before that it is necessary to set main roles or standards. In this situation, failure-elimination is the first step toward layer protection, and failure-control would be placed in the next layer. To reduce the consequences of failure, the last layer should be carefully positioned. According to findings during the survey, a suggestive concept has been recommended according to zoning theory, which fragments high-fire-risk forests to limit the fire aggression. A safety swath network is recommended based on this theory, with flexible width suggested of between 30 and 70 meters. This safety network could be augmented by a specified grid of a water mist network with the ability of humidifying approximately 100 meters of another zone with the application of a mobile sprinkler system. For populated areas, such as camping sites, a safety boundary has been proposed to isolate these risky areas from the forest. There are always activities that can stop autonomous disasters or reduce their consequences; our task is to find these activities and adhere to them. The aim of the study is to
\end{abstract}


condense existing literature in a collection and make new suggestions to improve forest treatment and make that knowledge accessible for students, researchers, and forest management systems. Reducing forest fire consequences would be our final goal in a responsive collaboration toward a safer future.

Keywords: layer protection, preventive and remedial measures, passive and active protection, zoning theory, safety swath network, safety mound network, safety boundary rand, water mist network.

\section{Introduction}

Flood, forest fire, landslide, storm, ozone depletion, air pollution, waste and garbage problems, and industrial accidents are some examples of natural or industrial disasters that almost every territory is subjected to. We might not be sure about the causes of these flourishing catastrophes, but their consequences are unbearable. Human interventions through climate change, fuel accumulation, ignition, and abandoned agricultural lands could be some of the reasons for an unusual number of wildfires. Meanwhile, intensive forest fires could have an amplification effect on themselves through adding their $\mathrm{CO}_{2}$ emission to the human share, inducing global warming and climate change.

Forest fire has damaged over 10 million hectares (ha) of Southern European forests in the two last decades [5]. Every year, in the Mediterranean Basin, wildfires burn down 700,000-1,000,000 ha of wildlands [6]. Throughout Europe this figure is about 500,000 ha of forested areas caused by 50,000 fires [7]. In Spain, during the last 40 years, forest and bush fires have burned down around $6,400,000$ ha of green-lands with economic damage of around 7.5 billion Euros [39]. Forest fire impact in Portugal is also significant - over 15 years (19902005 ) nearly $25 \%$ of the countries forest area has been burned, which is about 2.2 million ha [4].

In Sweden, forest fires have not been too extensive and they can be put out in less than a few hours. Apart from precipitation, access roads are very important in this regard and in Sweden the average span to a navigable road is between 400 and $500 \mathrm{~m}[16,17]$. The history of forest fire frequencies in northern Sweden show intervals of between 60 and 80 years [9, 13], while the average fire intervals in the boreal forests is between 50 and 200 years [17, 24]. According to a study published in 1998, mitigation of forest carbon emissions in some European countries can compensate $30-35 \%$ of their carbon emissions, while this figure in Sweden proved to be about 60\% [36].

All forest fires are bad and should be put out in a minimum time was fire policy in the US and after the death of 34 fire fighters during the fire season in 1994 , a concern about fire policy was raised in order to find better treatments for forest fires [41].

Canada owns more than $10 \%$ of the world's forest [31] and the forest industry contributes $\$ 33$ billion to the gross domestic products and directly employs 376,000 people [10]. Every year in Canada, almost 10,000 fires burn about 2.5-2.8 million ha of wildland areas, which are caused by human activity and lightning [20, 23, 31]. During the fire season, forest fire damage to public and 
private resources could easily reach hundreds of million dollars, while fire suppression expenses easily hit $\$ 1$ billion [10]. A burned area for one-wildfire in the range of 100,000 ha is not uncommon and 1 million ha has been recorded as well. Over 20 years (1980-2000) the mean burned area in Canada has increased dramatically [34]. Over the next century, considering climate change, wildfire severity could substantially increase so that by 2040 , in Canada, annually the burned area could be doubled and wildfire problems would go beyond our present and future capacity. On the other hand, forest fire exclusion could accumulate fuel and encourage insect infestation with the consequence of dead fuel accumulation and older non-healthy forests, which are good choices for wildfires [10].

Siberian forests are protected by one amazing natural effect, Permafrost, which preserves ice from rain water in the soil. Recently, increasing forest fires have raised absorption of solar radiation into the ground, disturbing the permafrost and changing forests to swamps or grasslands in an irreversible way [22]. The African continent owns two-thirds of the Earth's savannas and burning savannas in Africa play an important role in $\mathrm{CO}_{2}$ production [26].

Unwanted wildfires could be a threat to public health, property, forest services and non-market values, while forest fires would improve the biodiversity, health and productivity of the forest ecosystem, considering the biological, ecological and physical characteristics of wildland fires that could be performed through natural or prescribed fires. Risk identification and fire management, including public education, preparedness, response, mitigation, recovery, and land management by fire, are essential activities for improving forest health [12], in which risk could be defined as the likelihood of an unwanted and unpleasant incident and its probable consequences [3, 27].

Bio-fuel in the forest could be a source of energy for humans, but if forest management systems do not take additional fuel at the right time, fires would take it, resulting in unbearable consequences. There are important issues in forests, which impose adverse impacts on human life and the environment. Meanwhile, some of them could be availed for human use and somehow preclude damage to the environment. Discrimination and confusion are two essential facts that should be distinguished among different causes and effects of forest fires, so that clear intuition through different parameters in the forest emerges. For example, the "All forest fires are bad" concept has been changed to new and more realistic concepts.

\section{Materials and methods}

Through the review study, more than ten years of experience in industrial safety and fire fighting is combined with new findings in the forest fire field. Articles, scientific papers, and web-pages have been studied and reviewed to find points and comments that might help to reduce fire occurrence probabilities, fire aggression, and damage to people, the environment, and the economy. A HSE (Health, Safety, Environment) industrial plan has played an important role in connecting industrial concepts of safety to forest fire facts (Fig. 1). In the first 
step, it has attempted to extract results from literature to be used in the concept of layer protection, which is adapted from the industrial safety and fire fighting context. This concept is introduced to the study by means of preventive and remedial measures, which are two main schemes for reducing unwanted incidents and their probable consequences.

\section{Results: a suggestive concept}

Among existing ways of controlling wildfires, forest management may consider conventional fuel treatment, including thinning, branch pruning, bush and slash removal and some extra precautionary measures, such as fuel breaks, access roads, introducing high fire resistance plants and keeping a low surface fuel load, utilizing domestic animals [8]. In many countries, there are effective activities for forest fuel management and risk mitigation, but it is difficult to do this for all territories and countries. However, forest fires should be kept in a rational, moderate, and controllable criterion. Systematic suppression, fuel accumulation throughout years without regular fuel reduction, and above all drought, has made forests vulnerable to fire. As a result, high fuel density forests provide suitable conditions for intensive fires [3]. Different forests should have their own policies, depending on the management ability of the fuel control. It would also be possible to try new suggestions that limit the fire progress in a specific

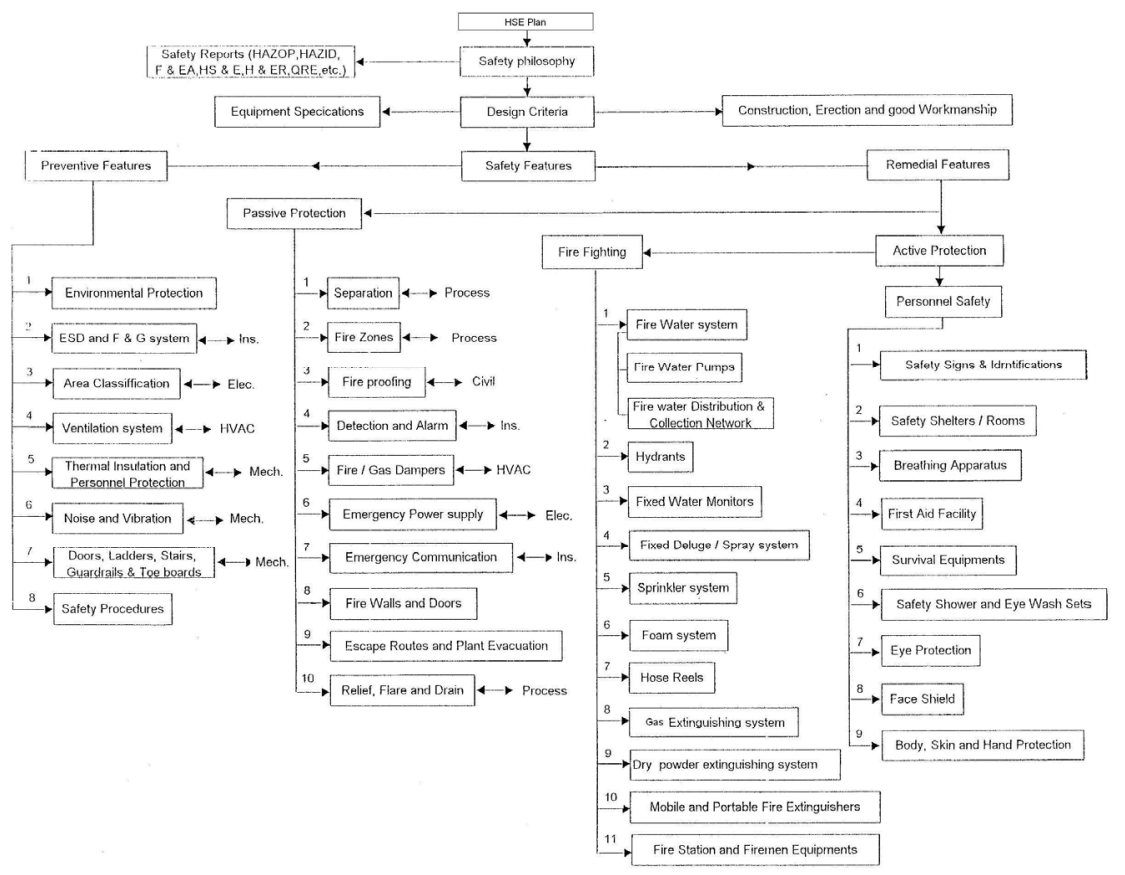

Figure 1: HSE industrial plan as the study base. 
manner. According to the above mentioned HSE plan, fire protection could be divided into two main sections: passive and active protection. Separation and fire zoning are pivotal aspects in passive fire protection, which could be utilized in forest fire protection. Accordingly, some suggestions will be discussed according to these aspects and in future works they might be developed to theoretical and operational activities. For many months and years, it would not be rational to wait for fire, despite having equipment, which most probably is not adequate when wildfire attacks.

\subsection{Zoning theory}

There could be a simple and unique solution for many kinds of forests against wildfires, which is the application of Zoning Theory. This theory would divide the forest into different zone areas. We might not be able to specify an area size description for all territories, but each country could decide the size of the zone area according to its territory, fire risk, and equipment. Forest fires could be divided into easy, difficult, and impossible to be tackled by the fire management system. Accordingly, fire consequences through this kind of management might be tolerable, laborious, and insupportable, respectively. Depending on fire types, the area size might be small or extensive and of any shape or topographic configuration. For instance, a forest with an easy-to-tackle condition could have a larger zone area than another forest with difficult conditions.

To be more understandable, an area of 400 ha - any geometric shape driven from the territory, or $2.0 \mathrm{Km}$ by $2.0 \mathrm{Km}$ - could be considered for a territory with medium fire risk as a base zone area, which is less than the considered area for the "zone" in other documents [14, 42]. Among different areas, there might be zones with high or low fire risk and in turn, zone-areas would be smaller or larger, respectively. The zone-area could be very limited in a region with arson risk. Within the zone-area fire would be suppressed or the forest itself would be able to limit the fire in one or maximum two zones. If the forest has reached the time for prescribed burning - prescribed natural fire - or there are limitations to our extinguishing ability, or the fire goes wild, it would be allowed to burn, since it cannot burn more than itself - our battery limit.

Through this zoning theory, there is the possibility to order areas based on their fire season. For example, if we decide to put a 100 year interval for fire, zone patches would be scattered and fire occurrences in one zone would be confronted with non-uniform forest textures and this could be one step toward controlling the fire. For example, we would have a 20 year interval between patches that start from 0 and continue to $20,40,60,80$, and 100 year zone-area patches.

This could be a basis for the least infrastructure for every forested territory that has suffered from fire. In the Cape of Creus, NE of Catalonia, Spain, there are areas that have been burned five times just during the 21 years from 1975 to 1995 [33]. These areas could be a good choice for applying zoning theory. There would also be special a dynamic fire-break between zones, named the Safety Swath. 


\subsection{Safety swath network}

Roads and access-ways are fundamental elements in limiting forest fire through their double acting phenomena, as a fire break and provider of rapid intervention. The safety swath is not a road but a developed space and the master key in Zoning Theory, which should protect and isolate zones as a fire break. It is called a dynamic because it could have dynamic specifications, such as non-fixed wideness or non-fixed moisture conditions (Fig. 2).

Performing this extensive infrastructure would take time and expenditure and it is better to be accomplished gradually - from high fire risk to low fire risk areas. It should be noted that if there are limitations to applying this theory, only high risk areas could be considered and all forest areas might not need this zoning system.

The cost of performing the safety swath could be its design, implementation, enforcement, and cleaning after one or two years. Special cutting could be done in the case of a fire incident, which is obviously an easy job having this infrastructure. In the case of outraging wildfires there would be a possibility of starting a back-fire from the other side of the zone and toward the wind direction to widen the safety swath.

This theory could also be applied in WUI and major-value-at-risk points. Apart from defensible space that protects every house, there would be a safety swath that isolates one zone from another. The area of the zone should be determined according to the fire risk and terrain conditions.

\subsection{Safety swath specification}

First and foremost the width of this safety band should be indicated. According to investigation through available documents, it should not be so narrow so as to act as a fire-ladder and not so wide that it cannot be handled. In the design condition, we speak carefully about 500-600 $\mathrm{m}$ for the width of a firebreak, but when it comes to a fire situation we look for just a 3 meter road. In practice there are 8-12 $\mathrm{m}$ firebreaks, including natural creeks, that functioning in a network [2]. It is suggested that the optimum distance of the forest from a house is about $50 \mathrm{~m}$ $[11,19,30,32,40]$, which could be an applicable figure after some considerations.

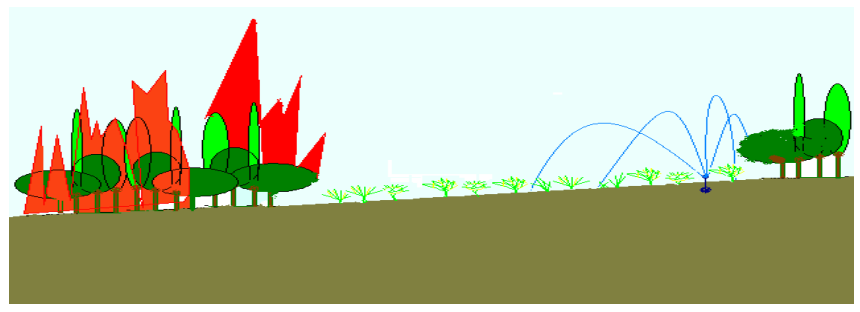

Figure 2: $\quad$ Safety swath network augmented by water mist network. 
If there are economical problems in providing a $50 \mathrm{~m}$ interval between zone areas, considering the prevailing-wind during the fire season, there would be a possibility of reducing the width of this safety band. To do this, the angle between the prevailing-wind during the fire season and the safety swath middle line $(\alpha)$ should be established. The following formula would be a good start for considering limitations:

$$
\text { Width }(\mathrm{m})=30+20 \operatorname{Sin}(\alpha) \quad\left(\text { slope }<5^{\circ}\right)
$$

As can be seen from this formula, $50 \mathrm{~m}$ has been divided into a base distance of $30 \mathrm{~m}$ plus a maximum $20 \mathrm{~m}$ variable.

According to the results detailed in the wind and slope section in the thesis [35], every $10^{\circ}$ slope change, up to $15^{\circ}$, would tilt the fire angle approximately $15^{\circ}$. Considering the maximum $40 \mathrm{~m}$ for flame length, there would be around $10 \mathrm{~m}$ flame displacement, $\mathrm{D}=40 \operatorname{tg}\left(15^{\circ}\right)=10.7 \mathrm{~m}$. To compensate for this change and to increase the safety margin in maximum $15^{\circ}$ slopes, the width of this band might be increased by another $20 \mathrm{~m}$. Width $(\mathrm{m})=50+20\left(5^{\circ}<\right.$ slope $<$ $15^{\circ}$ ). For slopes more than $15^{\circ}$, further research is required. All of these assumptions have been suggested according to existing research results and require more detailed investigations. Fuel through this swath could be grass that would be treated by means of systematic grazing or machines - at least once in two years. Around particular zone-areas could be cleaned during fire incidents, which would not be a major task. Slopes that are facing toward the prevailingwind should be considered as more vulnerable areas and augmented with special features.

\subsection{Safety mound network: the second choice}

Since the forest terrain could somehow disrupt the fireline intensity $[1,15,18$, $25,29,37,38]$ in high fire risk areas, there would be the possibility of building a network of artificial mounds - 15 to $20 \mathrm{~m}$ high - along with specific considerations. Trees should not grow on the mound and it could be protected by the water-mist network (Fig. 3). In this way, the mound would absorb the radiation energy of wildfire and present a good opportunity to put out the wildfire. On the other hand, at the other side of the mound, wind speed would be restricted and the fire has less tendency to come down in the location of the fire fighters who are there to put it out. Washing by rain and construction expenses are two important problems with this choice.

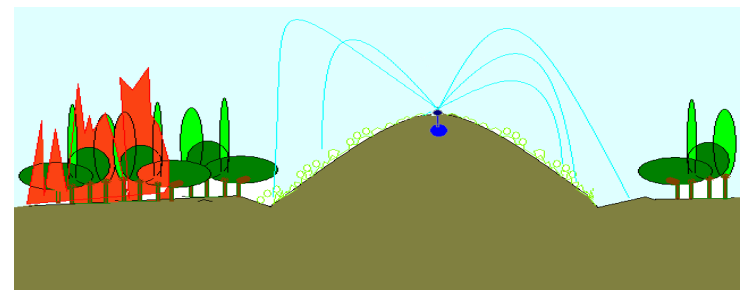

Figure 3: $\quad$ Safety mound network augmented with water mist system. 


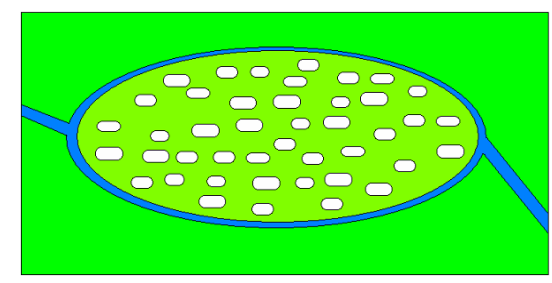

Figure 4: A schematic diagram for SBR, applicable to a camping area.

\subsection{Safety boundary rand (SBR)}

Forest crossing roads or railways, camping areas, and other civil centers should be equipped with SBR, which could start at least $20 \mathrm{~m}$ from the edge. This rand should be protected and cleaned from easily flammable shrubs, teasels, and bushes. To protect camping and recreation centers, it would be a good idea to place these important areas in natural or artificial islands as safety boundary rands. Through this scheming, forests would, to some extent, be protected and these infrastructures would also be protected from fire. In addition, these surrounding rivers or water rings would bring more a pleasant environment to camping and recreation centers - e.g. fishing activities (Fig. 4).

\subsection{Water mist network}

After evaluating fire risk through all territories, all high fire risk zones could be considered in the water mist network concept. This network applies along with the safety swath or the safety mound to add more support to our fire break during intense fires (Fig. 5). Most fire prone areas could be protected by this water mist protection, which would humidify at least $100 \mathrm{~m}$ of another zone.

There is a suggestion for applying a mobile sprinkler system as a safety band to increase the resistance against fire - particularly in water restricted areas. To fight fire directly, there must be at least $3-5 \mathrm{lit} / \mathrm{m}^{2}$ water available, while applying the safety sprinkler system would require only 1 lit/m ${ }^{2}[21,28]$. Considering the protection of one side of the zone area with this concept, the protected area should be considered as $2000 \mathrm{~m}$ (as the zone-area side) by $100 \mathrm{~m}$ (as depth of safety band) $=200,000 \mathrm{~m}^{2}$. Accordingly, the amount of required water would be $1 \mathrm{lit} / \mathrm{m}^{2}$ X $200,000 \mathrm{~m}^{2}=200 \mathrm{~m}^{3}$. The progress of fire in grasslands is relatively high and about $1100 \mathrm{~m} / \mathrm{h}$ [43], which could be considered as a basis for calculation. As a result, the time for humidification could be considered as one hour. This means that $200 \mathrm{~m}^{3} / \mathrm{h}$ is required to protect $2000 \mathrm{~m}$ on one side of the zone area through portable sprinklers.

After the management system accepts the water mist protection, this network would be provided in high fire danger areas according to the mentioned hypothesis (Fig. 5). To bring this concept under economical consideration and according to water requirements $\left(200 \mathrm{~m}^{3} / \mathrm{h}\right)$, an underground network of 4 inch plastic pipe could be considered. Presuming this pipe size, the maximum water velocity in the pipe would be $3.6 \mathrm{~m} / \mathrm{s}$ which is an acceptable velocity. 


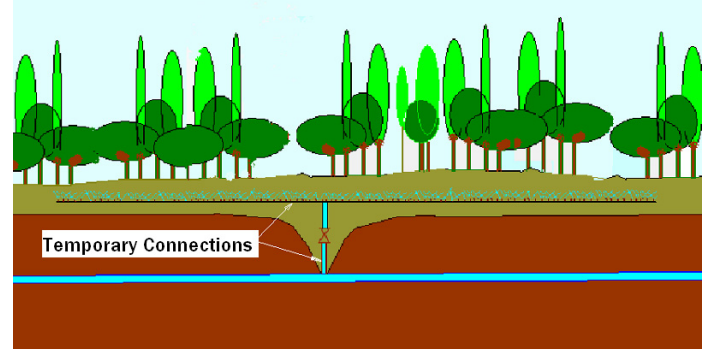

Figure 5: A schematic diagram for the water mist system.

The installation of a portable water mist sprinkler on an existing underground network would not be a time consuming job. Assuming $100 \mathrm{~m}$ for each portable water mist package, 20 fast-connections should be made on the main underground plastic pipe. Another quick alternative would be a $2000 \mathrm{~m}$ package, which should be connected to the network at two end points.

Providing quick access to fire water for fire trucks could be another advantage of this water network. In addition, distributed fire-water storage basins, particularly in elevated areas for hastening the fire fighting process, are effective forest fire repressors as fast providers of fire-water for fire trucks, air-tankers and the possible network system. Further experimental tests and calculations are required to establish final conditions based on this theory.

\subsection{Soil improvement}

Preserving water in the soil like Permafrost could be one effective way of protecting forests from fire through adding high water absorbent gels to the soil after evaluating the economic and possible side effects of this method. Soil water content is an important parameter in starting forest fires and there is room for research in soil improvement, such as high water absorbent gels, which could be tested and introduced to thin-soil areas or soils with low water tenability to improve water composition in the soil.

\section{Discussion}

In industry, usually the mentioned safety configuration plan has been used (Fig. 1). In the case of forest fire many of those fire controlling aspects could be applied. Summarizing all the mentioned steps and activities, the following forest rescue plan as a block diagram (Fig. 6) has been prepared based on study results and prior experiences. It starts with the preparation of an environmental and safety philosophy including, safety reports. The preparation of design criteria would be the next step, including forest and job specifications. In the case of forest fire, passive protection is combined with preventive measures under the safety feature box. 


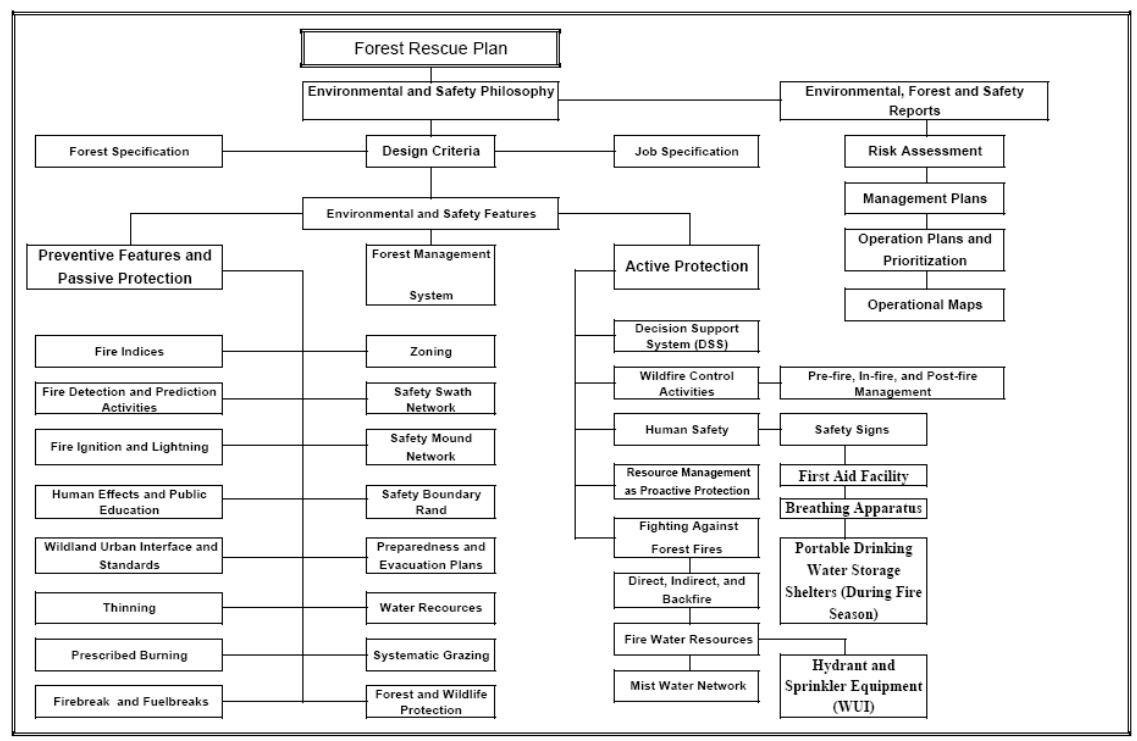

Figure 6: Forest rescue plan.

Passive protection could be part of forest management or activities that are done to reduce the risks of a probable fire, such as zoning, instant fire alarms, human and environmental protection. Preventive measures contain a wide range of actions, including people training and forest management.

In active protection human protection should warrant the most attention and afterwards there would be fighting against fire, utilizing different kinds of equipment to overcome the fire. A decision support system, resource management, fighting methods, and wildfire control activities are placed under the active protection box.

There are many points and comments in reviewing thesis documents and here through this paper some specific results have been discussed. There is room for investigating new and more-effective concepts, despite many improvements in managing forest fires. Among existing ways of controlling forest fires, there could be the possibility of trying new suggestions that limit the fire progress in a specific manner. Zoning theory is a simple, unique, and basic solution for many sorts of forests against wildfire. This theory would divide the forest into different zone areas. The zone-area could be very limited in a region with arson risk. Through this zoning theory, there is the possibility of ordering areas based on their fire seasons to make a non-uniform forest texture and thereby reducing wildfire aggressiveness.

\section{Acknowledgement}

The work is based on a master thesis with the supervision of Professor Håkan Torstensson. 


\section{References}

[1] Albini F.A., Behavior: A User's Manual. USDA Forest Service, Intermountain Forest and Range Experiment Station, Ogden, UT, 68 pp. 1976.

[2] Hoare Peter, A process for community and government cooperation to reduce the forest fire and smoke problem in Thailand, Agriculture, Ecosystems and Environment 104 (2004) 35-46.

[3] Roloff Gary J., Mealey Stephen P, Clay Christopher, Barry Jeff, Yanish Curt, Neuenschwander Leon, A process for modeling short and long-term risk in the southern Oregon Cascades, Forest Ecology and Management 211(2005)166-190.

[4] Carreiras Joao M.B., Pereira Jose' M.C., An inductive fire risk map for Portugal, Forest Ecology and Management 234S (2006) S56.

[5] Alonso-Betanzos Amparo, Fontenla-Romero Oscar, Guijarro-Berdinas Bertha, Hernandez-Pereira Elena, Andrade Maria Inmaculada Paz, Jimenez Eulogio, Soto Jose Luis Legido, Carballas Tarsy, An intelligent system for forest fire risk prediction and fire fighting management in Galicia, Expert Systems with Applications 25 (2003) 545-554.

[6] P. Fernandes, H. Botelho, Analysis of the prescribed burning practice in the pine forest of northwestern Portugal, Journal of Environmental Management 70 (2004) 15-26.

[7] Keramitsoglou Iphigenia, Kiranoudis Chris T., Sarimveis Haralambos, Sifakis Nicolaos, A Multidisciplinary Decision Support System for Forest Fire Crisis Management, Environmental Management Vol. 33, No. 2, pp. 212-225.

[8] Kaloudis Spiros, Tocatlidoub Athena, Lorentzos Nikos A., Sideridis Alexander B., Karteris Michael, Assessing Wildfire Destruction Danger: a Decision Support System Incorporating Uncertainty, Ecological Modelling 181 (2005) 25-38.

[9] Pahlén Tina, Att restaurera forna tiders beståndsstruktur. Ett exempel från Jämtgaveln, SLU, Institutionen för skoglig vegetationsekologi, Examensarbete i skoglig vegetationsekologi, juni 2000.

[10] A report to the Canadian Council of Forest Ministers, prepared by the Canadian Wildland Fire Strategy, Assistant Deputy Ministers Task Group, Canadian Council of Forest Ministers, 2005, Canadian wildland fire strategy: A vision for an innovative and integrated approach to management risks, Catalogue No. Fo134-1/2005E-PDF, ISBN 0-662-42195-7.

[11] Howard R.A., North D.W., Offensend F.L., Smart C.N., 1973. Decision Analysis of Fire Protection Strategy for the Santa Monica Mountains: an Initial Assessment. Stanford Research Institute, Menlo Park, CA.

[12] Canadian Council of forest ministers, Declaration of Canadian Wildland Fire Strategy, Saskatoon, Saskatchewan, 2005.

[13] Linder P. 1988. Jämtgaveln - En studie av brandhistorik, kulturpåverkan och urskogsvärden i ett mellannorrländskt skogsområde. Rapport 1988:3, Länsstyrelsen i Västernorrlands Län. Härnösand, Sweden. 
[14] Simard A., 1991. Fire severity, changing scales, and how things hang together. Int. J. Wildland Fire 1 (1), 23-34.

[15] Rothermel, R.C, 1983. Forest and Range Fires. Gen. Tech. Rep. INT-143. USDA, forest service, intermountain forest and range exp. sm. ogden, UT, $161 \mathrm{pp}$.

[16] Granström A. (1998): "Forest fire and fire management in Sweden". International Forest Fires News, no 18.

[17] López Jerónimo, Forest fires and fire management in Sweden; a comparison with Spain, Examensarbete Nr. 24, 2003, Institutionen för skogens produkter och marknader, SLU, ISSN 1651-4467.

[18] Rothermel, R.C., Wilson, Jr., R.A., Morris, G.A. and Sackett, S.S., 1986. Fuels: Input to the BEHAVE Fire Prediction System. Res. Pap. INT-359. USDA Forest Service, Intermountain Res. Stn. Ogden, UT. 61 pp.

[19] Collins Timothy W., Households, forests, and fire hazard vulnerability in the American West: A case study of a California community, Environmental Hazards 6 (2005) 23-37.

[20] Lee B.S., Alexander M.E., Hawkes B.C., Lynham T.J., Stocks B.J., Englefield P., Information systems in support of wildland fire management decision making in Canada, Computers and Electronics in Agriculture 37 (2002) 185-198.

[21] Linkewich A., 1972, Air attack on forest fires, DW. Friesen, Calgary.

[22] Chikahisa T., Anzai H., Hishinuma Y., Kudo K., Modeling and evaluating the effect of forest fire control on the $\mathrm{CO} 2$ cycle in Siberia, Energy 30 (2005) 2261-2274.

[23] Groot William J. de, Modeling Canadian wildland fire carbon emissions with the Boreal Fire Effects (BORFIRE) model, Forest Ecology and Management 234S (2006) S224.

[24] Schimmel J. (1993): "On fire: fire behaviour, fuel succession and vegetation response to fire in the Swedish boreal forest". Umeå, Sveriges Lantbruksuniversitet: Reprocentralen, SLU.

[25] Schroeder, M.J. and Buck, C.C., 1970.for Application of Meteorological Information to Forest Fire Control Operations. USDA Forest Service, Agricultural Handbook 360. US Government Printing Office, Washington, DC, 229 pp.

[26] Beaudoin Laurent, Gademer Antoine, Amir Ahmed, Avanthey Loica, Germain Vincent, Pocheau Alexandre, Near real time detection of hot spots on Meteosat Second Generation images : from forest fires to volcanic eruptions, 1-4244-1212-9/07/\$25.00 C2007 IEEE.

[27] Fairbrother Anne, Turnley Jessica G., Predicting risks of uncharacteristic wildfires: Application of the risk assessment process, Forest Ecology and Management 211 (2005) 28-35.

[28] Rickard Hansen, "Skogbrandsläckning”, Utgivningsår 2003, Räddningsverket, Sweden.

[29] Rothermel. R.C., 1972. Spread in WiIdland Fuels. Res. Pap. INT-115. USDA Forest Service, Intermountain Forest and Range Exp. Stn., Ogden, UT, 40 pp. 
[30] Foote, E.I.D., 1994. Structure survival on the 1990 Santa Barbara "Paint", fire: a retrospective study of urban-wildland interface fire hazard mitigation factors. M.S. Thesis, University of California, Berkeley.

[31] Li Z., Chilar J., Remote Sensing of Canadian Forest Fires: Hotspots, Burned Area, and Smoke Plumes, 0-7803-5207-6/99810.00, 1999 IEEE.

[32] Cohen Jack, Johnson Nan, Walther Lincoln, Saving Homes from Wildfires: Regulating the Home Ignition Zone, Zoning News, American Planning Association, APA, May 2001.

[33] Diaz-Delgado Ricardo, Pons Xavier, Spatial patterns of forest fires in Catalonia (NE of Spain) along the period 1975-1995, Analysis of vegetation recovery after fire, Forest Ecology and Management 147 (2001) 67-74.

[34] Podur Justin, Martell David L., Knight Keith, Statistical quality control analysis of forest fire activity in Canada, Can. J. For. Res. 32: 195-205 (2002).

[35] Morandini F., Santoni P.A., Balbi J.H., The contribution of radiant heat transfer to laboratory-scale fire spread under the in influences of wind and slope, Fire Safety Journal 36 (2001) 519-543.

[36] Nabuurs G. J., Paivinen R., Sikkema R., Mohren G. M. J., The role of European forest in the global carbon cycle-A review, Biomass and Bioenergy Vol. 13, No. 6, pp. 345-358, 1997.

[37] Kushla John D., Ripple William J., The role of terrain in a fire mosaic of a temperate coniferous forest, Forest Ecology and Management 9.5 (1997) 97- 107.

[38] Albini, F.A., Latham, D.J. and Baughman, R.G., 1982.Upslope Convective Windspeeds for Predicting Wildland Fire Behavior. Res. Paper NT-257. USDA Forest Service, Intermountain Forest and Range Exp. Stn., Ogden, UT, 19 pp.

[39] Nunez-Regueira Lisardo, Rodriguez-Anon Jose A., Proupn-Castineiras Jorge, Using calorimetry for determining the risk indices to prevent and fight forest fires, Thermochimica Acta 422 (2004) 81-87.

[40] Dombeck, M.P., Williams, J.E., Wood, C.A., 2004. Wildfire policy and public lands: integrating scientific understanding with social concerns across landscapes. Conservation Biology 18 (4), 883-889.

[41] http://www.csfs.colostate.edu/, Wildfire Policy in Transition, Colorado State Forest Service, Colorado State University (Consulted Nov. 2008).

[42] Hardy Colin C., Wildland fire hazard and risk: Problems, definitions, and context, Forest Ecology and Management 211 (2005) 73-82.

[43] Garnica J. G. F., Gonzalez D. A. M., Solorio J. D. B., Forest fire behaviour in prescribed burns under different environmental conditions in Mexico, Forest Ecology and Management 234S (2006) S131. 